\title{
Incidence and associated risk factors of cancer in patients after infective endocarditis hospitalization: A propensity score matched analysis
}

\author{
Hung Yi Chen, M.D. ${ }^{1,2}$
}

\begin{abstract}
Chen HY. Incidence and associated risk factors of cancer in patients after infective endocarditis hospitalization: A propensity score matched analysis. Curr Res Cardiol 2017;4 (3):29-34.

BACKGROUND: The relationship between infective endocarditis (IE) and malignancies had been reported. However, cancer development is multifactorial and mortality is high in IE survivors. We aimed to estimate the absolute cancer risk in IE survivors and tried to find the potential risk factors.

METHODS: This nationwide, population-based cohort study evaluated 8649 newly diagnosed IE who survived after discharge from first hospitalization using the Taiwan National Health Insurance Research Data-base (NHIRD). Propensity score method was used at a 1:1 ratio based on age, gender, income, urbanization level, Charlson comorbidity index (CCI), concomitant medication, and medical history. The primary outcomes were all specific cancer types. All the variables matched for propensity score were analyzed to find their association with cancer occurrence.
\end{abstract}

RESULTS: Compared with the matched cohort, IE survivors increase the risk of cancer (adjusted hazard ratio [aHR], 1.64; 95\% confidence interval [CI], 1.391.94), as well as significantly elevated risks of digestive (aHR, 2.27 ; 95\% CI, 1.76 2.92) and hematologic (aHR, 2.73; 95\% CI, 2.31-5.71) malignancies. Age (aHR, 1.47; 95\% CI, 1.36-1.57), male (aHR, 1.49; 95\% CI, 1.18-1.90), CCI score (aHR, $1.05 ; 95 \% \mathrm{CI}, 1.01-1.10$ ) are risk factors for cancer occurrence among IE survivors, while aspirin use reduced the cancer risk (aHR, 0.73; 95\% CI, 0.54-0.98).

CONCLUSION: Our study provides further investigation between IE and cancer risk. In conclusion, cancer risk, particularly digestive and hematologic malignancies, is substantially increased in IE survivors. Our results also provide additional evidence that aspirin use is effective in reducing cancer risk in IE survivors.

Key Words: Infective endocarditis; Cancer; Propensity score match; Aspirin
Increased morbidity and high mortality of cancer is the important global human health problem. Cancer formation is complicated and there are variable factors in cancer etiology. It has been evidenced that inherent genetic factor, smoking, alcohol consumption, radiation exposure, environmental pollutants contact and infectious agents are considered to be the potential risk for cancer development. In addition, geographic difference and socioeconomic status have been reported as important factors and used in cancer development and survive estimation (1-3). Recent reports have enhanced infection-associated cancers could be linked to geographic factor and socioeconomic development (4)

Infective endocarditis (IE) is a peculiar disease caused by microorganisms with clinical valvular endothelial damage. Although it is relative rare disease, the incidence rate of IE is various and dependent on different population with their different basic characteristics. Clinically, IE is not a disease with uniform presentation and the various manifestations make the diagnosis indistinct. Durack et al. using echocardiography for IE diagnosis grades the disease as certain, probable, and possible (5). The criteria have been used for IE diagnosis till now. Cancer process is slow and may take many years. In cancer patients without clinical manifestation, compromised immunity could be vulnerable to IE (6). Early observational studies demonstrated IE by some individual microorganisms could be linked to specific cancer occurrence as colorectal neoplasm (7).

Till now, cancer prevention is intractable. Despite there is no definite medication in prevention of cancer development at present time, many studies demonstrated the use of cardiovascular drugs as aspirin and statin were associated with lowering colorectal cancer risks (8-10). The relationship between IE and cancer had been reported, however, IE survivors with concomitant use of cardiovascular medication may impact on the results (11). In addition, IE is a complicated and serious infection disease and has a high mortality rate in both in-hospital and long-term follow-up $(12,13)$. This makes the categorical relationship between IE and cancer more difficult to clarify.

The aim of this study was to use the nationwide population-based database to explore the incidence of long-term cancer risk in IE survivor. We also tried to evaluate the associated risk factors in cancer development. To reduce the effects of potential confounders from baseline characteristics, we conducted a propensity score-matching study. To minimize death effect in IE patients, we used death as competing risk in regression analysis in the study.

\section{MATERIALS AND METHODS}

\section{Data sources}

The study was based on data from the NHIRD released by the National Health Research Institute (NHRI). The National Health Insurance (NHI) program was begun in 1995 and provided comprehensive health care for all Taiwan inhabitants. Enrollment in the NHI program is mandatory and there are presently more than 23 million enrollees, representing approximately 99\% of Taiwan's population (12). The NHIRD includes the entire registry and claims data from the NHI system, ranging from demographic data to detailed orders from ambulatory and inpatient care. The NHIRD is managed and publicly released by the NHRI, and contains registration files and original reimbursement claims data for all enrollees in Taiwan. Disease diagnoses were coded according to the International Classification of Disease, Ninth Revision, Clinical Modification (ICD-9-CM). The diagnostic accuracy for the major diseases in the NHIRD has been well validated (14).

The NHI specified 30 categories of catastrophic illness (e.g., cancer, chronic renal failure, autoimmune disease) to avoid severe financial load on families coping with major illness. Patients with catastrophic illness were free from copayments under the NHI program. Thus, if a patient was diagnosed with one category of the catastrophic illness, the attending physician submitted related information in application for a catastrophic certificate. The catastrophic illness certificate could not be identified without authorization.

All information that could potentially identify any individual patients was encrypted before the database was released. The confidentiality of the database was in accordance with the data regulations of the Bureau of $\mathrm{NHI}$ and the

${ }^{1}$ Division of Cardiology, Department of Medicine, Taipei City Hospital, Heping Fuyou Branch, Taipei, Taiwan, ${ }^{2}$ Institute of Public Health and Community Medicine Research center, National Yang-Ming University School of Medicine, Taipei, Taiwan

Correspondence: Dr Hung Yi Chen, MD, Division of Cardiology, Department of Medicine, Taipei City Hospital, Heping Fuyou Branch, Taipei, Taiwan, Telephone 886-22388-9595, e-mail anigi426@ms24.hinet.net

Received: May 21, 2017, Accepted: July 05, 2017, Published: July 07, 2017 
NHRI, Taiwan. The NHRI secured the privacy of all beneficiaries and provided health insurance data to researchers who obtained ethical approval.

\section{Study design}

This nationwide population-based, observational, retrospective cohort study aimed to determine the association between IE and subsequent cancers. We enrolled two cohorts in the study: the IE cohort and a matched cohort. The IE cohort was conducted from January 2000 to December 2009. To confirm the diagnosis of IE, we extracted the cohort from the entire original NHIRD, consisted of first time discharged patients with an IE diagnosis (ICD-9-CM code: 421.0, 421.1, and 421.9) who received antibiotic treatment during hospitalization. The included reliable IE diagnosis was based on the revised Duke criteria (15). The agreement of code IE diagnosis in Taiwan NHIRD with that of clinical definite or possible IE in a tertiary center in Taiwan had been validated (16). We excluded patient with the following characteristics: age $<20$ years, prior history of IE, and mortality during hospitalization for IE. Patients with malignancy diagnosis upon initial diagnosis of IE were also excluded. We defined the index date as the first day of discharge from IE. We extracted the control cohort from the Longitudinal Health Insurance Database, a subset of the original NHIRD, which contains data from a random sample of 1 million NHI beneficiaries. The exclusion criteria for the control cohort were the same as IE cohort. Index date for subjects in the control cohort were randomly assigned and corresponded to those patients in the IE cohort.

To avoid the influences of baseline differences as household income, urbanization level, concomitant medications, comorbidities, and coexisting condition, propensity score method was used with 1:1 matching and we calculated for the likelihood of hospitalization for IE using the baseline covariates and multivariate logistic regression analysis. One control patient was matched with each IE cohort patient with similar propensity score based on nearest neighbor matching without replacement using calipers of width equal to 0.1 standard deviation of the logit of the propensity score.

\section{Outcomes}

The main dependent outcome in this study was the primary cancer incidence in patients with IE. The diagnosis of cancer was identified using the records of the Catastrophic Illness Patient Database. The diagnostic codes of cancers were defined as those from 140 to 208.91 in the ICD-9-CM format. Malignant neoplasm of ill-defined sites (ICD-9-CM 195) and secondary cancers (ICD9-CM 196-199) were excluded. All subjects were followed until death, loss to follow-up, or 31 December 2010.

\section{Baseline characteristics}

We included baseline demographic characteristics as age, gender, monthly income (NT\$<19,100, NT\$19,100-41,999, and NT\$> 42.000), urbanization, and Charlson Comorbidity Index (CCI) score. According to the Taiwan NHRI, urbanization levels in Taiwan are divided into four strata. The most urbanized areas are designated as level 1 , and the least urbanized areas as level 4. Systemic health is determined by CCI score, and each increase in score indicates a stepwise increase in cumulative mortality (17). Other systemic diseases related to general health not included in the CCI were also evaluated including coronary artery disease, dyslipidemia, end-stage renal disease, arterial fibrillation, pre-existing valvular heart disease, and drug abuse. We also extracted concomitant use of medications that could be associated with cancer risk when discharge following IE as aspirin, clopidogrel, ticlopidine, and statin $(8,18)$.

\section{Statistical analysis}

The baseline characteristics of the study cohorts were analyzed using descriptive statistics. The Pearson $\mathrm{X}^{2}$ test was used to compare the baseline characteristics of the two cohort groups for categorical variables and the independent t-test for parametric continuous variables. Propensity score of the likelihood of IE were determinate by multivariate logistic regression analysis, conditional on baseline covariates (19). We used cox regression models with a conditional approach using stratification to calculate adjusted hazard ratios (aHRs) and 95\% confidence intervals (CIs) for the risk of cancer in each group. Due to the high mortality rate in patients with IE, competingrisk regression using Fine and Gray's model was also performed (20). The Kaplan-Meier method was used to estimate the cumulative incidence of cancers, and the log-rank test was used to evaluate the differences between the two cohorts.

Data linkage, processing, and sampling were done by the SQL Server 2012 (Microsoft Corporation, Redmond, Washington, USA). We used SAS version 9.3 (SAS Institute, Cary, North Carolina, USA) for propensity scores calculation. The STATA statistical software (version 12.0; Stata Corp Texas, USA) was used for conducting all other statistical analysis. Statistical significance was defined as $\mathrm{P}<0.05$.

\section{RESULTS}

Demographic and clinical characteristics

During the study periods, 8,690 patients hospitalized for the first episode of IE between January 2000 and December 2009 were enrolled, including $5,766(66.4 \%)$ males and 2,924 (33.5\%) female, with the male to female

TABLE 1

Demographic and clinical characteristics of study population

Propensity score-matched

\begin{tabular}{|c|c|c|c|c|c|}
\hline Characteristic & & $\begin{array}{l}\text { All } \\
\text { patients } \\
\text { with IE }\end{array}$ & $\begin{array}{l}\text { Patients } \\
\text { with IE }\end{array}$ & $\begin{array}{l}\text { Matched } \\
\text { Control }\end{array}$ & $P$ Value \\
\hline $\begin{array}{l}\text { Number of } \\
\text { patients }\end{array}$ & & 8,690 & 8,649 & 8,649 & \\
\hline $\begin{array}{c}\text { Mean age }(S D), \\
\text { years }\end{array}$ & & $\begin{array}{c}52.9 \\
(18.9)\end{array}$ & $53.0(18.9)$ & 53.0 & 0.998 \\
\hline Male & & $\begin{array}{l}5,766 \\
(66.4)\end{array}$ & $\begin{array}{l}5,734 \\
(66.3)\end{array}$ & $\begin{array}{l}5,729 \\
(66.2)\end{array}$ & 0.936 \\
\hline \multirow[t]{4}{*}{ Monthly income } & Dependent & $\begin{array}{l}2,041 \\
(23.5)\end{array}$ & $\begin{array}{l}2,038 \\
(23.6)\end{array}$ & $\begin{array}{l}2,038 \\
(23.6)\end{array}$ & 1 \\
\hline & NT\$0-19,100 & $\begin{array}{l}2,907 \\
(33.5)\end{array}$ & $\begin{array}{l}2,877 \\
(33.3)\end{array}$ & $\begin{array}{l}2,882 \\
(33.3)\end{array}$ & \\
\hline & $\begin{array}{c}\text { NT } \$ 19,100- \\
42,000\end{array}$ & $\begin{array}{l}2,907 \\
(33.5)\end{array}$ & $\begin{array}{l}3,404 \\
(39.4)\end{array}$ & $\begin{array}{l}3,399 \\
(39.3)\end{array}$ & \\
\hline & $>$ NT $\$ 42,000$ & $330(3.8)$ & $330(3.8)$ & $330(3.8$ & \\
\hline \multirow[t]{4}{*}{$\begin{array}{l}\text { Urbanization } \\
\text { level }\end{array}$} & 1 & $\begin{array}{l}4,349 \\
(50.0)\end{array}$ & $\begin{array}{l}4,329 \\
(50.1)\end{array}$ & $\begin{array}{l}4,335 \\
(50.1)\end{array}$ & 1 \\
\hline & 2 & $\begin{array}{l}3,436 \\
(39.5)\end{array}$ & $\begin{array}{l}3,423 \\
(39.6)\end{array}$ & $\begin{array}{l}3,416 \\
(39.5)\end{array}$ & \\
\hline & 3 & $750(8.6)$ & $743(8.6)$ & $744(8.6)$ & \\
\hline & 4 (rural) & 155 (1.8) & $154(1.8)$ & $154(1.8)$ & \\
\hline \multirow[t]{4}{*}{$\begin{array}{l}\text { Charlson } \\
\text { Comorbidity } \\
\text { Index score }\end{array}$} & 0 & $\begin{array}{l}1,378 \\
(15.9)\end{array}$ & $\begin{array}{l}1,378 \\
(15.9)\end{array}$ & $\begin{array}{l}1,378 \\
(15.9)\end{array}$ & 1 \\
\hline & 1 & $\begin{array}{l}1,646 \\
(18.9)\end{array}$ & $\begin{array}{l}1,644 \\
(19.0)\end{array}$ & $\begin{array}{l}1,641 \\
(19.0)\end{array}$ & \\
\hline & 2 & $\begin{array}{l}1,400 \\
(16.1)\end{array}$ & $\begin{array}{l}1,395 \\
(16.1)\end{array}$ & $\begin{array}{l}1,398 \\
(16.2)\end{array}$ & \\
\hline & $\geq 3$ & $\begin{array}{l}4,266 \\
(49.1)\end{array}$ & $\begin{array}{l}4,232 \\
(48.9)\end{array}$ & $\begin{array}{l}4,232 \\
(48.9)\end{array}$ & \\
\hline \multirow[t]{4}{*}{$\begin{array}{l}\text { Concomitant } \\
\text { medications }\end{array}$} & Aspirin & $\begin{array}{l}1,306 \\
(15.0)\end{array}$ & $\begin{array}{l}1,306 \\
(15.1)\end{array}$ & $\begin{array}{l}1,305 \\
(15.1)\end{array}$ & 0.983 \\
\hline & Clopidogrel & $221(2.5)$ & $221(2.6)$ & $219(2.5)$ & 0.923 \\
\hline & Ticlopidine & $89(1.0)$ & $89(1.0)$ & $89(1.0)$ & 1 \\
\hline & Statin & $298(3.4)$ & $298(3.4)$ & $301(3.5)$ & 0.901 \\
\hline \multirow[t]{11}{*}{ History of } & Diabetes & $\begin{array}{l}2,549 \\
(29.3)\end{array}$ & $\begin{array}{l}2,541 \\
(29.4)\end{array}$ & $\begin{array}{l}2,541 \\
(29.4)\end{array}$ & 1 \\
\hline & Hypertension & $\begin{array}{l}4,195 \\
(48.3)\end{array}$ & $\begin{array}{l}4,186 \\
(48.4)\end{array}$ & $\begin{array}{l}4,185 \\
(48.4)\end{array}$ & 0.988 \\
\hline & $\begin{array}{c}\text { Cerebrovascular } \\
\text { disease }\end{array}$ & $\begin{array}{l}2,510 \\
(28.9)\end{array}$ & $\begin{array}{l}2,505 \\
(29.0)\end{array}$ & $\begin{array}{l}2,509 \\
(29.0)\end{array}$ & 0.947 \\
\hline & $\begin{array}{l}\text { Coronary artery } \\
\text { disease }\end{array}$ & $\begin{array}{l}3,030 \\
(34.9)\end{array}$ & $\begin{array}{l}3,026 \\
(35.0)\end{array}$ & $\begin{array}{l}3,026 \\
(35.0)\end{array}$ & 1 \\
\hline & $\begin{array}{l}\text { Myocardial } \\
\text { infarction }\end{array}$ & $537(6.2)$ & $537(6.2)$ & $538(6.2)$ & 0.975 \\
\hline & Heart failure & $\begin{array}{l}2,944 \\
(33.9)\end{array}$ & $\begin{array}{l}2,919 \\
(33.7)\end{array}$ & $\begin{array}{l}2,917 \\
(33.7)\end{array}$ & 0.874 \\
\hline & Dyslipidemia & $\begin{array}{l}2,079 \\
(23.9)\end{array}$ & $\begin{array}{l}2,074 \\
(24.0)\end{array}$ & $\begin{array}{l}2,078 \\
(24.0)\end{array}$ & 0.943 \\
\hline & $\begin{array}{l}\text { End-stage renal } \\
\text { disease }\end{array}$ & $569(6.5)$ & $565(6.5)$ & $563(6.5)$ & 0.951 \\
\hline & $\begin{array}{l}\text { Chronic kidney } \\
\text { disease }\end{array}$ & $\begin{array}{l}1,851 \\
(21.3)\end{array}$ & $\begin{array}{l}1,841 \\
(21.3)\end{array}$ & $\begin{array}{l}1,842 \\
(21.3)\end{array}$ & 0.985 \\
\hline & Atrial fibrillation & $961(11.1)$ & $961(11.1)$ & $910(10.5)$ & 0.212 \\
\hline & AIDS & $116(1.3)$ & $97(1.1)$ & $97(1.1)$ & 1 \\
\hline
\end{tabular}




\begin{tabular}{|c|c|c|c|c|}
\hline Drug abuse & $\begin{array}{l}1,032 \\
(11.9)\end{array}$ & $966(11.2)$ & $993(11.5)$ & 0.943 \\
\hline $\begin{array}{c}\text { Valve } \\
\text { replacement } \\
\text { with mechanical } \\
\text { valve }\end{array}$ & $856(9.9)$ & $851(9.8)$ & & \\
\hline $\begin{array}{c}\text { Valve } \\
\text { replacement } \\
\text { with } \\
\text { bioprosthetic } \\
\text { valve }\end{array}$ & $470(5.4)$ & $469(5.4)$ & & \\
\hline
\end{tabular}

TABLE 2

Associations between infective endocarditis and risks of cancer gender ratio about 2.0. The mean age of the IE cohort was 52.9 (SD, 18.9) years. After propensity score matching, we enrolled 8,649 patients with IE and 8,649 matched cohorts in the study (Table 1).

Cancer risk in IE patients without previous history of malignancy

There were 334 patients diagnosed with cancer during the follow-up periods after discharge from hospitalization due to IE. The aHR for risk of cancer was 1.64 (95\% CI, 1.39 to 1.94 ). The cumulative incidence of all cancer risk in patients with IE and the matched cohort was illustrated in Figure 1.

When stratified by gender, increased risks for all cancers remained in both males (aHR, 1.75; 95\% CI, 1.43-2.14) and females (aHR, 1.43; 95\% CI, 1.07

\begin{tabular}{|c|c|c|c|c|c|c|c|c|c|c|c|}
\hline & & & & & & & & \multicolumn{4}{|c|}{ Propensity Score-Matched } \\
\hline & & \multicolumn{3}{|c|}{ IE cohort } & \multicolumn{3}{|c|}{ Control cohort } & \multicolumn{2}{|c|}{ Crude } & \multicolumn{2}{|c|}{$\begin{array}{c}\text { Competing } \\
\text { risk }^{\ddagger}\end{array}$} \\
\hline & & No. of Event & Person-years & Incidence rate* & No. of Event & $\begin{array}{l}\text { Person- } \\
\text { years }\end{array}$ & Incidence rate* & $\begin{array}{c}\text { Hazard } \\
\text { Ratio } \\
(95 \% \\
\text { Cl) }\end{array}$ & $p$ Value & $\begin{array}{c}\text { Hazard } \\
\text { Ratio } \\
(95 \% \\
\text { Cl) }\end{array}$ & $p$ Value \\
\hline \multirow[t]{2}{*}{ All } & All cancer & 334 & 36798 & 90.77 & 244 & 44185 & 55.22 & $\begin{array}{c}1.64 \\
(1.39- \\
1.94)\end{array}$ & $<0.001$ & $\begin{array}{c}1.36 \\
(1.15- \\
1.60)\end{array}$ & $<0.001$ \\
\hline & Death & 3118 & 37421 & 833.23 & 1502 & 44636 & 336.5 & $\begin{array}{c}2.41 \\
(2.27- \\
2.56)\end{array}$ & $<0.001$ & & \\
\hline \multirow[t]{2}{*}{ Male } & All cancer & 236 & 24575 & 96.03 & 160 & 29064 & 55.05 & $\begin{array}{c}1.75 \\
(1.43- \\
2.14)\end{array}$ & $<0.001$ & $\begin{array}{c}1.46 \\
(1.19- \\
1.78)\end{array}$ & $<0.001$ \\
\hline & Death & 2040 & 25010 & 815.66 & 1003 & 341.86 & 341.86 & $\begin{array}{l}2.33 \\
(2.16- \\
2.51)\end{array}$ & $<0.001$ & & \\
\hline \multirow[t]{2}{*}{ Female } & All cancer & 98 & 12223 & 80.18 & 84 & 15121 & 55.55 & $\begin{array}{c}1.43 \\
(1.07- \\
1.91)\end{array}$ & 0.017 & $\begin{array}{c}1.16 \\
(0.87- \\
1.55)\end{array}$ & 0.316 \\
\hline & Death & 1078 & 12410 & 868.65 & 499 & 15296 & 326.22 & $\begin{array}{c}2.57 \\
(2.31- \\
2.86)\end{array}$ & $<0.001$ & & \\
\hline
\end{tabular}

*per 104 person-years.

t Adjusted for propensity score.

¥Death was calculated as a competing risk in this model.

Interaction p-value for sex was 0.298 .

IE: Infective endocarditis; Cl: Confidence Interval

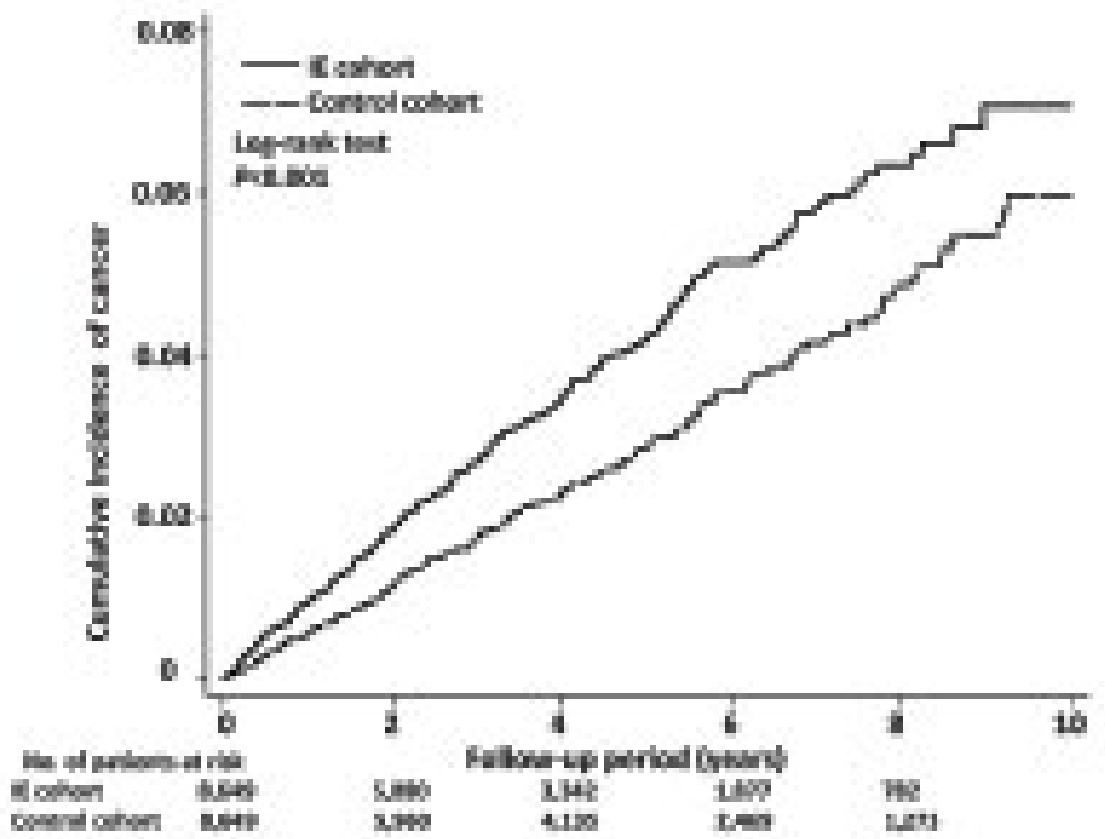

Figure 1) Cumulative incidence of cancer among patients with infective endocarditis and control cohort 
TABLE 3

Associations between infective endocarditis and risks of cancer

\begin{tabular}{ccc} 
& Adjusted HR $^{*}(\mathbf{9 5} \% \mathbf{C l})$ & $\boldsymbol{P}$-Value \\
\hline $\begin{array}{c}\text { Primary analysis } \\
\begin{array}{c}\text { Excluding patients with } \\
\text { up }^{\dagger}\end{array}\end{array}$ & $1.64(1.39-1.94)$ & $<0.001$ \\
\hline $\begin{array}{c}\text { Excluding patients with }<2 \text { years follow } \\
\text { up }^{\ddagger}\end{array}$ & $1.42(1.19-1.71)$ & $<0.001$ \\
\hline
\end{tabular}

TABLE 4

Associations between infective endocarditis and risks of different site of cancer

\begin{tabular}{|c|c|c|c|c|c|c|c|}
\hline & & & & & & $\begin{array}{l}\text { Propensit } \\
\text { Score-Ma }\end{array}$ & $\begin{array}{l}\text { ity } \\
\text { atched }\end{array}$ \\
\hline & & IE cohc & & Contro & I cohort & Crude & \\
\hline \multicolumn{2}{|l|}{ Type of cancer } & $\begin{array}{l}\text { No. of } \\
\text { Event }\end{array}$ & $\begin{array}{l}\text { Incidence } \\
\text { rate* }\end{array}$ & $\begin{array}{l}\text { No. of } \\
\text { Event }\end{array}$ & $\begin{array}{l}\text { Incidence } \\
\text { rate* }\end{array}$ & $\begin{array}{l}\text { Hazard } \\
\text { Ratio } \\
(95 \% \mathrm{Cl})\end{array}$ & $p$ Value \\
\hline \multicolumn{2}{|l|}{ All cancer } & 334 & 90.77 & 244 & 55.22 & $\begin{array}{l}1.64 \\
(1.39- \\
1.94)\end{array}$ & $<0.001$ \\
\hline \multicolumn{2}{|l|}{ Head and neck } & 30 & 8.15 & 19 & 4.3 & $\begin{array}{l}1.93 \\
(1.08- \\
3.43)\end{array}$ & 0.025 \\
\hline \multirow[t]{6}{*}{ Digestive } & & 172 & 46.74 & 92 & 20.82 & $\begin{array}{l}2.27 \\
(1.76- \\
2.92)\end{array}$ & $<0.001$ \\
\hline & Esophagus & 17 & 4.62 & 2 & 0.45 & $\begin{array}{l}10.29 \\
(2.37- \\
44.56)\end{array}$ & 0.002 \\
\hline & Stomach & 11 & 29.89 & 8 & 18.11 & $\begin{array}{l}1.63 \\
(0.65- \\
4.04)\end{array}$ & 0.296 \\
\hline & $\begin{array}{l}\text { Colon and } \\
\text { rectum }\end{array}$ & 71 & 19.3 & 34 & 7.7 & $\begin{array}{l}2.56 \\
(1.70- \\
3.86)\end{array}$ & $<0.001$ \\
\hline & $\begin{array}{l}\text { Liver and } \\
\text { biliary tract }\end{array}$ & 64 & 17.39 & 38 & 8.6 & $\begin{array}{l}2.04 \\
(1.36- \\
3.05)\end{array}$ & 0.001 \\
\hline & Pancreas & 8 & 2.17 & 8 & 1.81 & $\begin{array}{l}1.18 \\
(0.44- \\
3.13)\end{array}$ & 0.746 \\
\hline $\begin{array}{l}\text { Lung and } \\
\text { mediastinum }\end{array}$ & & 27 & 7.34 & 27 & 6.11 & $\begin{array}{l}1.20 \\
(0.70- \\
2.05)\end{array}$ & 0.499 \\
\hline $\begin{array}{l}\text { Bone and soft } \\
\text { tissue }\end{array}$ & & 4 & 1.09 & 3 & 0.68 & $\begin{array}{l}1.53 \\
(0.34- \\
6.86) \\
\end{array}$ & 0.574 \\
\hline $\begin{array}{l}\text { Bone and soft } \\
\text { tissue }\end{array}$ & & 7 & 1.9 & 2 & 0.45 & $\begin{array}{l}4.06 \\
(0.84- \\
19.54)\end{array}$ & 0.081 \\
\hline Breast & & 10 & 2.72 & 13 & 2.94 & $\begin{array}{l}0.93 \\
(0.41- \\
2.11)\end{array}$ & 0.856 \\
\hline \multirow[t]{7}{*}{ Genitourinary } & & 44 & 11.96 & 62 & 14.03 & $\begin{array}{l}0.84 \\
(0.57- \\
1.24)\end{array}$ & 0.389 \\
\hline & Cervix $^{\dagger}$ & 8 & 6.55 & 3 & 1.98 & $\begin{array}{l}3.21 \\
(0.85- \\
12.10)\end{array}$ & 0.085 \\
\hline & Uterus $^{\dagger}$ & 0 & 0 & 3 & 1.98 & & \\
\hline & Ovary $^{\dagger}$ & 3 & 2.45 & 2 & 1.32 & $\begin{array}{l}1.81 \\
(0.30- \\
10.86)\end{array}$ & 0.515 \\
\hline & Prostate ${ }^{\ddagger}$ & 16 & 6.51 & 17 & 5.85 & $\begin{array}{l}1.10 \\
(0.56- \\
2.18)\end{array}$ & 0.778 \\
\hline & Bladder & 8 & 2.17 & 16 & 3.62 & $\begin{array}{l}0.59 \\
(0.25- \\
1.38)\end{array}$ & 0.224 \\
\hline & Kidney & 6 & 1.63 & 20 & 4.53 & $\begin{array}{l}0.36 \\
(0.15- \\
0.90)\end{array}$ & 0.029 \\
\hline CNS & & 1 & 0.27 & 3 & 0.68 & $\begin{array}{l}0.43 \\
(0.04- \\
4.12)\end{array}$ & 0.462 \\
\hline
\end{tabular}

\begin{tabular}{|c|c|c|c|c|c|c|}
\hline Thyroid & 2 & 0.54 & 4 & 0.91 & $\begin{array}{l}0.61 \\
(0.11- \\
3.34)\end{array}$ & 0.571 \\
\hline Hematologic & 24 & 6.52 & 10 & 2.26 & $\begin{array}{l}2.73 \\
(1.31- \\
5.71)\end{array}$ & 0.008 \\
\hline
\end{tabular}

*per 104 person-years.

tOnly female included in this analysis.

fOnly male included in this analysis.

IE: Infective endocarditis; Cl: Confidence interval

1.91). When death was calculated as a competing risk in this model, the aHR was 1.36 (95\% CI, 1.15 to 1.60$)$. The associations between IE and subsequent cancer is shown in Table 2 .

With regards to specific cancer types, the risk of head and neck (HR, 1.93; 95\% CI, 1.08-3.43), esophagus (HR, 10.29; 95\% CI, 2.37-44.56), colon and rectum (HR, 2.56; 95\% CI, 1.70-3.86), liver and biliary tract (HR, 2.04; 95\% $\mathrm{CI}, 1.36-3.05)$, and hematologic malignancies (HR, 2.73; 95\% CI, 1.31-5.71) were significantly higher in patients with IE. The associations between IE and risks of different site of cancer are listed in Table 4.

Risk factors for cancer after the diagnosis of IE

In Cox multivariate proportional hazard analysis, age, per 10-year (HR, 1.47; 95\% CI, 1.36-1.57), males (HR, 1.49; 95\% CI, 1.18-1.90), and Charlson comorbid index score (HR, 1.05; 95\% CI, 1.01-1.10) were independent risk

\section{TABLE 5}

Risk factor for cancer events among patients with infective endocarditis

\begin{tabular}{ccc} 
& $\begin{array}{c}\text { Hazard Ratio }(95 \% \\
\text { CI) }\end{array}$ & $\boldsymbol{p}$ Value \\
\hline Age, per 10 years & $1.47(1.36-1.57)$ & $<0.001$ \\
Male & $1.49(1.18-1.90)$ & 0.001 \\
Drug abuse & $0.35(0.17-0.73)$ & 0.005 \\
Charlson Comorbid Index score, per 1 score & $1.05(1.01-1.10)$ & 0.021 \\
Aspirin & $0.73(0.54-0.98)$ & 0.036
\end{tabular}

*Adjusted all covariate lists in Table 1.

*Only significant factors were shown in this table.

$\mathrm{Cl}$ : Confidence interval; IE: Infective endocarditis

factors for cancer risk in patients with IE. Aspirin use (HR, 0.73; 95\% CI, 0.54-0.98), and drug abuse ( $\mathrm{HR}, 0.35 ; 95 \% \mathrm{CI}, 0.17-0.73$ ) were found to decrease cancer risks. Risk factors for cancer development and IE were listed in Table 5.

\section{DISCUSSION}

Cancer process is multistage, and cancerous growth forms as the result of a sequence of events over a period of time. To reduce the influence of possible confounders in cancer development, propensity score method has been used to decrease possible confounders in studies for cancer risk $(21,22)$. Clinically, IE patients have a high mortality rate both in-hospital and follow-up, and cancer process is slow and may take many years. It is difficult to assay the categorical relationship between the two diseases. In studying cancer risk and prognosis, death could be a potential factor influences the results. And competing mortality has been widely used in evaluating cancer risks and outcomes to minimize the effect $(23,24)$. Our study demonstrates a significantly increased cancer risk in newly diagnosed IE patients than propensity score-matched group. Results of the current study show the increased risk in cancer occurrence in head/neck, digestive, and hematologic system. Our data also demonstrates the cancer risk in different cancer types, and suggests the cancer risk is prominent in digestive cancer, particularly in colorectal neoplasm. This is consistent with prior data. Cancer patients without clinical manifestation with compromised immunity could be vulnerable to IE $(6,11)$. Increased the incidence of peri-diagnosis of IE in elderly cancer patients has been demonstrated (25). Despite the causal relationship is not clear, our results provide further evidence in the association between IE and cancer risk, and the risk remains high in 10-year follow-up. This is the first main finding in our study. 
Considering all of the variables include in Table 1 to find their association with cancer risk, the results show age, gender, CCI score increase the cancer risk. While aspirin use decreases cancer risk in IE survivors. This is another main finding in our study. Similar effect is not found in clopidogrel, ticlopidine, and statin use. Although true mechanism is uncertain, there were experimental, epidemiologic, and clinical evidences about aspirin use in lowering cancer development, particular for colorectal cancer (26). Some studies demonstrated aspirin use offered protection in esophageal and stomach cancer, despite the effect was not prominent as colorectal cancer (27). The effect of aspirin in reducing cancer risk of non-gastrointestinal tract also had been documented $(28,29)$. As for IE, the benefic and risk of aspirin use has been researched, however, whether aspirin therapy is associated with better outcomes in IE patients remains controversial. In addition to the effect of embolic events prevention, some studies demonstrated aspirin use reduced vegetation enlargement and decreased occurrence of acute valve replacement surgery in IE patients, but without lowering cancer incidence $(30,31)$. Investigations of IE are limited because IE is the disease with low incidence, hard for diagnosis, and the latency period between initial symptom and definite diagnosis. Although we do not perform specific cancer analysis, our data suggests aspirin therapy could low overall cancer risk in IE survivors. As for the benefits and risks from aspirin in IE survivors, further assessment of the advantage and disadvantage is required. Our data also demonstrates decreasing cancer risks in drug abuse. We do not have any explanation for the result. We assume a condition that drug abuser may have less regular medical follow-up and record than general population, and has a less cancer detection rate. However, the true reason needs further evaluation.

Our study demonstrates cancer risk is high in IE patients with 10-year follow up, whether IE increases cancer risk or is a substantial marker for presence of occult cancer remains unclear. The major strengths of the current study are the case definition, its population-based design, 10-year study periods, and its complete coverage of IE and cancer patients in the population, wherein the possibility of loss to follow-up is essentially precluded. In addition, to reduce the effects of possible confounding, we use propensity score-matched control subjects in comparison with a general population.

Some limitations of our study should be considered. First, this is an epidemiologic study, a causative link between IE and cancer can't be established. Secondary, although we tried to use propensity score method to avoid possible confounders, detailed individual information as personal habits, family history, life style, and environmental exposure were not included in claims data. Also, we cannot identify the microorganisms related to IE. Third, certain carcinogenesis may need a longer time for cancer development. Although our study included 10-year follow-up, the follow-up duration could be relative short. Our study provides further investigation between IE and cancer risk.

\section{CONCLUSION}

In conclusion, cancer risk, particularly digestive and hematologic malignancies, is substantially increased in IE survivors. The effect remains greater during 10-year follow-up. Our results also provide additional evidence that aspirin use is effective in reducing overall cancer risk in IE survivors.

\section{ACKNOWLEDGMENTS}

This study was based in part on data from the NHIRD provided by Bureau of National Health Insurance (BNHI) of the Department of Health and managed by the NHRI. The conclusions presented in this study are those of the authors and do not necessarily reflect the views of the BNHI, the Department of Health, or the National Health Research Institute.

\section{GRANT SUPPORT}

None.

\section{REFERENCES}

1. Are C, Chowdhury S, Ahmad H, et al. Predictive global trends in the incidence and mortality of pancreatic cancer base on geographic location, socio-economic status, and demographic shift. J Surg Oncol 2016;114:736-42.

2. Shen X, Wang L, Zhu L. Spatial analysis of regional factors and lung cancer mortality in China, 1973-2013. Cancer Epidemiol Biomarkers Prev 2017;26:569-77.

3. Singer S, Bartels M, Briest $\mathrm{S}$, et al. Socio-economic disparities in longterm cancer survival-10-year follow-up with individual patient data. Support Care Cancer 2016;25:1391-9.

4. Plummer M, De Martel C, Vignat J, et al. Global burden of cancers attributable to infections in 2012: A synthetic analysis. Lancet Global Health 2016;4:e609-16.

5. Durack D, Lukes A, Bright D. New criteria for diagnosis of infective endocarditis: utilization of specific echocardiographic findings. Am J Med 1994;96:200-8.

6. Mesa Del Castillo-Paya C, Rodriguez-Esteban M, Quijada-Fumero A, et al. Infective endocarditis in patients with oncological diseases. Enferm Infecc Microbiol Clin 2016;S0213-005X (16):30344-5.

7. Sharara AI, Abou HT, Malli A, et al. Association of Streptococcus bovis endocarditis and advanced colorectal neoplasma: A case-control study. J Dig Dis 2013;14:382-7.

8. Simon MS, Rosenberg CA, Rodabough RJ, et al. Prospective analysis of association between use of statins or other lipid-lowering agents and colorectal cancer risk. Ann Epidemiol 2012;22:17-27.

9. Friis $\mathrm{S}$, Riis $\mathrm{AH}$, Erichsen R, et al. Low-dose aspirin or nonsteroidal antiinflammatory drug use and colorectal cancer risk: a population-based, case-control study. Ann Intern Med 2015;163:347-55.

10. Nan H, Hutter CM, Lin Y, et al. Association of aspirin and NSAID use with risk of colorectal cancer according to genetic variants. JAMA 2015;313:1133-42.

11. Thomsen RW, Farkas DK, Friis S, et al. Endocarditis and risk of cancer: a Danish nationwide cohort study. Am J Med 2013;126:58-67.

12. Cresti A, Chiavarelli M, Scalese M, et al. Epidemiological and mortality trends in infective endocarditits, A 17-year population-based prospective study. Caridovasc Diagn Ther 2017;7:27-35.

13. Shih CJ, Chu H, Chao PW, et al. Long-term clinical outcome of major adverse cardiac events in survivors of infective endocarditis: A nationwide population-based study. Circulation 2014;130:1684-91.

14. Cheng CL, Kao YH, Lin SJ, et al. Validation of the National Health Insurance Research Database with ischemic stroke cases in Taiwan. Pharmacoepidemiol Drug Saf 2011;20:236-42.

15. Heiro M, Helenius $\mathrm{H}$, Hurme S, et al. Long-term outcome of infective endocarditis: A study on patients surviving over one year after the initial episode treated in a Finnish teaching hospital during 25 years. BMC Infect Dis 2008;8:49.

16. Chen SJ, Chao TF, Lin YJ, et al. Cool seasons are related to poor prognosis in patients with infective endocarditis. Int J Biometeorol 2012;56:973-81.

17. Charlson ME, Pompei P, Ales KL, et al. A new method of classifying prognostic comorbidity in longitudinal studies: Development and validation. J Chronic Dis 1987;40:373-83.

18. Hicks BM, Murray LJ, Hughes C, et al. Clopidogrel use and cancer-specific mortality: A population-based cohort study of colorectal, breast and prostate cancer patients. Pharmacoepidemiol Drug Saf 2015;24:830-40.

19. Austin PC. A critical appraisal of propensity-score matching in the medical literature between 1996 and 2003. Stat Med 2008;27:2037-49.

20. Fine JP, Gray RJ. A proportional hazards model for the subdistribution of a competing risk. J Am Stat Assoc 1999;94:496-509.

21. Yu TM, Chuang YW, Yu MC, et al. Risk of cancer in patients with polycystic kidney disease: A propensity-score matched analysis of a nationbased cohort study. Lancet Oncol 2016;17:1419-25

22. Hsiang JC, Wong GL, Tse YK, et al. Statin and the risk of hepatocellular carcinoma and death in a hospital-based hepatitis B-infected population: A propensity score landmark analysis. J Hepatol 2015;63:1190-7.

23. Yanik EL, Katki HA, Engels EA. Cancer risk among the HIV-infected elderly in the United States. AIDS 2016;30:1663-8.

24. Ishida Y, Aiu D, Maeda M, et al. Secondary cancers after a childhood cancer diagnosis: A nationwide hospital-based retrospective cohort study in Japan. Int J Clin Oncol 2016;21:506-16.

25. Garcia-Albeniz X, Hsu J, Lipsitch M, et al. Infective endocarditis and cancer in the elderly. Eur J Epidemiol 2016;31:41-9.

26. Rothwell PM, Wilson M, Elsin CE, et al. Long-term effect of aspirin on colorectal cancer incidence and mortality: 20-year follow-up of five randomized trials. Lancet 2010;376:1741-50.

27. Cao Y, Nishihara R, Wu K, et al. Population-wide impact of long-term use of aspirin and the risk for cancer. JAMA oncol 2016;2:762-9. 


\section{Chen}

28.Zhong S, Chen L, Zhang X, et al. Aspirin use and risk of breast cancer. Systemic review and meta-analysis of observational studies. Cancer Epidemiol Biomarkers Prev 2015;24:1645-55.

29. Lapi F, Levi M, Simonetti M, et al. Risk of prostate cancer in low-dose aspirin users: A retrospective cohort study. Int J Cancer 2016;139:205-11.
30. Eisen DP, Corey GR, McBryde ES, et al. Reduced valve replacement surgery and complication rate in Staphylococcus aureus endocarditis patients receiving acetyl-salicylic acid. J Infect 2009;58:332-8.

31. Veloso TR, Oechslin F, Que YA, et al. Aspirin plus ticlopidine prevented experimental endocarditis due to Enterococcus faecalis and Streptococcus gallolyticus. Pathog Dis 2015;73: ftv060. 